\title{
Self-reported medication adherence and pharmacy refill adherence among persons with ischemic stroke: a cross-sectional study
}

\author{
Helena Norberg ${ }^{1}\left(\mathbb{D} \cdot\right.$ Maria Sjölander $^{1}\left([) \cdot\right.$ Eva-Lotta $_{\text {Glader }}^{2}(\mathbb{D}) \cdot$ Maria Gustafsson $^{1}(\mathbb{C}$
}

Received: 5 November 2021 / Accepted: 24 January 2022 / Published online: 14 February 2022

(c) The Author(s) 2022

\begin{abstract}
Purpose To describe and compare self-reported medication adherence assessed with the 5-item version of Medication Adherence Report Scale (MARS-5) and pharmacy refill adherence based on data from the Swedish Prescribed Drug Register (SPDR) among persons with ischemic stroke, and to investigate independent predictors associated with respective assessments.

Methods A study questionnaire was sent to persons with ischemic stroke registered in the Swedish Stroke Register between Dec 2011 and March 2012, and who lived at home 3 months after discharge. The primary outcome was dichotomized to adherent/non-adherent based on MARS-5 and SPDR and analyzed with multivariable logistic regression. Adherence according to MARS-5 was defined as score 23 or higher (out of 25). Adherence according to SPDR was defined as at least one filled statin prescription recorded in SPDR in each 6-month interval during 2 years of follow-up.

Results Of 420 participants, $367(87 \%)$ and 329 (78\%) were adherent according to MARS-5 and SPDR, respectively, and 294 (70\%) participants were adherent according to both assessments. A significant association was shown between medication adherence according to the two assessments $(p=0.020)$. Independent predictors associated with medication adherence according to MARS- 5 were female sex, while factors associated with SPDR were male sex and being younger.

Conclusions The majority of participants were classified as adherent, $87 \%$ according to MARS-5 and $78 \%$ based on data from SPDR. However, only 70\% were adherent according to both MARS-5 and SPDR, and different predictors were associated with the different measurements, suggesting that these assessments are measuring different aspects of adherence.
\end{abstract}

Keywords Ischemic stroke $\cdot$ Medication adherence $\cdot$ Self-reported adherence $\cdot$ Pharmacy refill adherence $\cdot$ MARS- $5 \cdot$ The Swedish Prescribed Drug Register

\section{Introduction}

Good adherence to medicines has a positive impact on health outcomes [1]. Unfortunately, poor medication adherence continues to be a major health challenge worldwide [2].

Prescription of statins is an established preventative treatment after ischemic stroke used to reduce recurrent cardiovascular events and mortality [3-6]. Previous studies have shown that good adherence to statin therapy is associated with reduced risk of recurrent stroke, myocardial infarction,

Helena Norberg

helena.norberg@umu.se

1 Department of Integrative Medical Biology, Umeå University, S-901 87 Umea, Sweden

2 Department of Public Health and Clinical Medicine, Umeå University, S-901 87 Umea, Sweden and all-cause death [7-10]. Satisfactory adherence to statins can also improve functional outcomes in persons with ischemic stroke [11]. However, adherence to long-term treatment of chronic disease decreases with time after diagnosis [12-14], and it has been shown that up to a third of statin users are non-adherent 6 months after their stroke event [15], even though improvement of statin adherence could reduce the risk of stroke [16]. To improve medication adherence, it is important to understand that adherence to any drug therapy regimen is multifaceted and requires both motivation and ability. Non-adherence could be either unintentional (forgetting to take medication) or intentional (missing/altering doses to suit one's needs), and these aspects of adherence have to be managed differently $[2,17]$.

There are several methods available for estimating adherence to drug therapy. To assess self-reported medication adherence, the 5-item version of the Medication 
Adherence Report Scale (MARS-5) can be applied. MARS-5 has been validated in different populations and settings, where medication refill adherence or certain surrogate markers have been used as reference [18-22]. To assess pharmacy refill adherence, it is common to analyze the drug supply, e.g., by estimating the proportion of days covered with medication or prescription refills within specified intervals. The Swedish Prescribed Drug Register (SPDR) provides data on all dispensed medicines in Swedish pharmacies and can be used to assess pharmacy refill adherence in Sweden. However, to the best of our knowledge, the relationship between self-reported adherence assessed with MARS-5 and pharmacy refill adherence assessed with SPDR has not been rigorously studied, nor has the question been asked which independent factors are related to these different methods for estimating medication adherence.

The aim of this contribution is to describe and compare self-reported medication adherence assessed with MARS-5 and pharmacy refill adherence based on data from SPDR among persons with ischemic stroke, and to investigate independent predictors associated with the two methods of assessment.

\section{Methods}

\section{Design and study participants}

A cross-sectional study was performed with questionnaire data on self-reported medication adherence assessed with MARS-5, clinical data from the Swedish stroke register (Riksstroke), and pharmacy refill data based on data from SPDR. The MARS-5 questionnaire and the stroke register follow-up questionnaire were sent to the study participants 3 months after their stroke events. Pharmacy refill data was limited to prescription refills of statins for up to 2 years after the participants were discharged from the hospital.

The study participants (previously described in [23]) were individuals with stroke who were registered in Riksstroke between December 2011 and March 2012. Riksstroke had an estimated coverage of $90.5 \%$ of all stroke events in 2011 and includes all 74 hospitals that treat acute stroke in Sweden. In this study, 25 out of the 74 hospitals volunteered to participate, and these institutions represented both rural and urban areas.

Inclusion criteria were as follows: persons who (i) had an ischemic stroke, (ii) were living at home 3 months after their stroke event, (iii) had a fully completed MARS-5 questionnaire, (iv) had filled at least one statin prescription within the first 6 months after discharge from the hospital, and (v) were alive at 2-year follow-up.

\section{Self-reported medication adherence}

Self-reported medication adherence was assessed using MARS-5 [21, 24]. The MARS-5 questionnaire consists of five statements, each describing a common non-adherent behavior. The respondents rate how often they behave as described by the various statements (I forget to take my medicines, I alter the dose of my medicines, I stop taking my medicines for a while, I decide to skip a dose, I take less than instructed $)$ on a 5-point Likert scale $(1=$ always, $5=$ never $)$. The first question focuses on unintentional nonadherence, while the other four questions reflect intentional non-adherence. MARS-5 total scores may range from 5 to 25 , with higher scores indicating better medication adherence. The outcome variable was dichotomized in logistic regression analyses, according to the total score on MARS-5, where adherence was defined as scores 23-25 and non-adherence as scores 5-22.

\section{Prescription refill adherence}

A more objective assessment of medication adherence were conducted based on retrospective pharmacy dispensation data recorded in SPDR [25]. The register was started in 2005 and provides information on all prescribed medicines dispensed at all Swedish pharmacies. The register is complete for all residents in Sweden and contains data with unique patient identifiers for all dispensed prescriptions. Information about prescriptions dispensed is transferred once per month to the National Board of Health and Welfare, which is responsible for SPDR. All drugs are classified according to the Anatomical Therapeutic Chemical (ATC) classification system. The register contains for example data on age, sex, and the history of medications prescribed and dispensed. However, information about how many days were supplied of prescribed medications is not available in SPDR.

Statins were chosen as follow-up medication because they are one of the guideline-recommended preventive drugs for persons with ischemic stroke [6]. Statins are prescribed to be taken once per day, which makes the estimates of adherence according to pharmacy refills in SPDR more reliable. The participants' refills of statin prescriptions were followed in 6-month intervals for a maximum of 2 years after discharge from the hospital. The 6-month intervals were considered appropriate because the Swedish state subsidizes drugs if each refill corresponds to a maximum estimated 3 months' supply, and a further grace period of 3 months were allowed in this study.

Pharmacy refill adherence to statins based on data from SPDR was used as a dichotomized outcome variable in logistic regression analyses. Participants were defined as 
adherent if they had at least one filled statin prescription recorded in SPDR within each 6-month interval after discharge from hospital during 2-year follow-up. Participants were defined as non-adherent if they did not refill a statin prescription in any of the remaining 3 follow-up intervals after the first 6-month period.

\section{Statistical analysis}

Study population characteristics are presented as mean and standard deviation (SD) or frequencies and percentages. Characteristics were compared between subgroups using Student's $t$-test for continuous variables and chi-squared test for categorical variables. The association between adherence according to MARS-5 and SPDR was examined using chisquared test. Multivariable logistic regression models were constructed to explore independent predictors of medication adherence associated with the dependent variable adherent/ non-adherent according to MARS-5 and SPDR respectively. The following independent variables were hypothesized to possibly have an impact on medication adherence and were therefore included in both regression models: age, sex, history of stroke, low level of consciousness at admission, living alone, self-reported dependence on relatives for help and support, and self-reported difficulties with memory. Age was the only continuous variable, and all other independent variables were categorical. The variable dependent on help/support from relatives were analyzed as dichotomous (yes/no), where yes included both alternatives yes (partially) and yes (completely). $P$ values $<0.05$ were considered statistically significant. Data were analyzed in IBM SPSS Statistics V.25.0.

\section{Results}

The study questionnaires were sent to a total of 797 people who were living at home 3 months after their stroke. Out of these 797, 594 individuals returned the questionnaires. Excluded from these 594 individuals were people who were not alive at the end of the 2-year follow-up $(n=34)$, people with stroke other than ischemic stroke $(n=49)$, people with not fully completed MARS-5 questionnaire $(n=49)$, people with no prescription of statins after discharge $(n=109)$, and people who had not filled at least one statin prescription within the first 6 months after hospital discharge $(n=13)$. After applying all inclusion criteria, 420 individuals were eligible and were included in the study.

Study population characteristics are shown in Table 1. An additional analysis showed no differences in characteristics between the original invited group $(n=797)$ versus study group $(n=420)$, or between the group that returned the questionnaires $(n=594)$ versus study group $(n=420)$ (Supplementary Table S1).
Table 1 Study population characteristics

\begin{tabular}{|c|c|}
\hline Characteristics & $\begin{array}{l}\text { Study population } \\
(n=420)\end{array}$ \\
\hline Age (years), mean \pm SD & $70 \pm 11$ \\
\hline \multicolumn{2}{|l|}{ Age (years), $n(\%)$} \\
\hline Age $<75$ & $262(62)$ \\
\hline Age $\geq 75$ & $158(38)$ \\
\hline \multicolumn{2}{|l|}{ Sex, $n(\%)$} \\
\hline Men & $253(60)$ \\
\hline Women & $167(40)$ \\
\hline \multicolumn{2}{|c|}{ Low level of consciousness at admission, $n(\%)$} \\
\hline No & $406(97)$ \\
\hline Yes (drowsy or unconscious) & $13(3)$ \\
\hline \multicolumn{2}{|l|}{ History of stroke, $n(\%)$} \\
\hline No & $355(85)$ \\
\hline Yes & $64(15)$ \\
\hline \multicolumn{2}{|c|}{3 months follow-up (self-reported data from questionnaire) } \\
\hline \multicolumn{2}{|l|}{ Living alone, $n(\%)$} \\
\hline No & $291(69)$ \\
\hline Yes & $124(30)$ \\
\hline \multicolumn{2}{|c|}{ Dependence on relatives for help/support, $n(\%)$} \\
\hline No & $229(55)$ \\
\hline Yes (partially) & $152(36)$ \\
\hline Yes (completely) & $24(6)$ \\
\hline \multicolumn{2}{|l|}{ Difficulties with memory, $n(\%)$} \\
\hline Never or almost never & $170(41)$ \\
\hline Sometimes & $190(45)$ \\
\hline Often or constantly & $51(12)$ \\
\hline
\end{tabular}

Of the 420 participants, 367 (87\%) were categorized by the MARS-5 questionnaire as adherent and $53(13 \%)$ as nonadherent. The mean MARS-5 score was 23.9 with a range 8-25 and was positively skewed, with half of the respondents (51\%) scoring 25. An overview of the MARS-5 results is shown in Table 2.

According to the SPDR investigation, 329 (78\%) of the 420 participants had purchased at least one statin prescription in each 6-month interval at the 2-year follow-up and were therefore classified as adherent, while $91(22 \%)$ individuals had no record of refilling statins in one or more of the follow-up intervals and were therefore classified as nonadherent. The groups were comparable in all characteristics except age and sex, where the non-adherent group $(n=91)$ were significantly older $(73 \pm 11$ vs $69 \pm 11$ years, $p=0.006)$ and had a higher proportion of women $(52 \%$ vs $36.5 \%$, $p=0.009)$ compared with the adherent group $(n=329)$ (data not shown). Over time, the number of individuals who filled a statin prescription in each 6-month interval declined (Fig. 1). In total, 364 (87\%) participants refilled their statin prescriptions in three out of the four 6-month follow-up 
Table 2 Overview of MARS-5 scores and its individual items

\begin{tabular}{|c|c|c|c|c|c|c|}
\hline MARS questions & Mean \pm SD & $\begin{array}{l}\text { Always }=1, \\
n(\%)\end{array}$ & $\begin{array}{l}\text { Often }=2, \\
n(\%)\end{array}$ & $\begin{array}{l}\text { Sometimes = 3, } \\
n(\%)\end{array}$ & $\begin{array}{l}\text { Rarely }=4, \\
n(\%)\end{array}$ & $\begin{array}{l}\text { Never }=5, \\
n(\%)\end{array}$ \\
\hline Item 1: "I forget to take my medicines" & $4.49 \pm 0.72$ & $1(0.2)$ & $5(1.2)$ & $34(8.1)$ & $129(30.7)$ & $251(59.8)$ \\
\hline $\begin{array}{l}\text { Item 2: "I alter the dose of my } \\
\text { medicines" }\end{array}$ & $4.82 \pm 0.55$ & $3(0.7)$ & $0(0)$ & $13(3.1)$ & $38(9.0)$ & $366(87.1)$ \\
\hline $\begin{array}{l}\text { Item 3: "I stop taking my medicines for } \\
\text { a while" }\end{array}$ & $4.89 \pm 0.42$ & $1(0.2)$ & $1(0.2)$ & $7(1.7)$ & $27(6.4)$ & $384(91.4)$ \\
\hline Item 4: "I decide to skip a dose" & $4.90 \pm 0.38$ & $1(0.2)$ & $0(0)$ & $6(1.4)$ & $26(6.2)$ & $387(92.1)$ \\
\hline Item 5: "I take less than instructed" & $4.84 \pm 0.53$ & $2(0.5)$ & $2(0.5)$ & $12(2.9)$ & $28(6.7)$ & $376(89.5)$ \\
\hline
\end{tabular}

MARS Medication Adherence Report Scale, SD Standard Deviation

intervals, and 390 (93\%) participants refilled their statin prescription in two out of the four 6-month intervals.

Table 3 presents adherence according to MARS-5 and SPDR. Overall, 294 (70\%) out of 420 participants were adherent according to both MARS-5 and SPDR. Twenty percent of the respondents who were adherent according to MARS-5 were non-adherent according to SPDR, and $11 \%$ of the respondents who were adherent according to SPDR were non-adherent according to MARS-5. A significant association was shown between medication adherence according to MARS-5 and SPDR $(p=0.020)$.

Multivariable logistic regression models for independent predictors of medication adherence associated with MARS-5 and SPDR are presented in Figs. 2 and 3. When medication adherence was assessed with MARS-5, women had 3.6 times higher odds of being adherent than men (OR

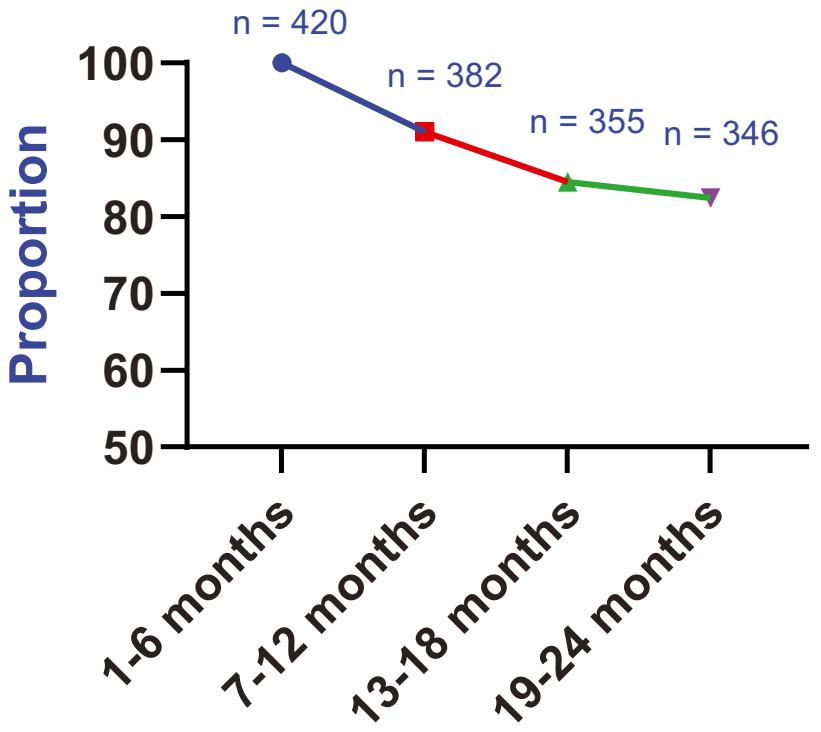

Fig. 1 The proportion of individuals who had a registered statin prescription refill according to the Swedish Prescribed Drug Register (SPDR) in each separate 6-month interval at the 2-year follow-up (not cumulative)
3.58, 95\% CI 1.63-7.86). Medication adherence according to pharmacy refills from SPDR was independently associated with age and sex. For every year increase, respondents had 3\% lower odds of being adherent (OR 0.97, 95\% CI 0.94-0.99). Women had 0.5 times lower odds of being classified as adherent (OR 0.50, 95\% CI 0.29-0.85) than men.

\section{Discussion}

The majority of persons with ischemic stroke adhered to their prescribed statins, according to both self-reported medication adherence (MARS-5) and as assessed by prescription refills based on data from SPDR. However, only $70 \%$ of the participants were adherent both according to MARS-5 and according to SPDR, which indicates that these assessments probably represent different aspects of medication adherence. Differences between the two types of assessments were also shown in terms of independent predictors where medication adherence according to MARS-5 was associated with female sex, while medication adherence based on data from SPDR was associated with male sex and being younger.

Table 3 Self-reported adherence assessed with the Medication Adherence Report Scale (MARS-5) versus pharmacy refill adherence based on data from the Swedish Prescribed Drug Register (SPDR) $(p=0.020)$

\begin{tabular}{lllll}
\hline & & \multicolumn{2}{l}{$\begin{array}{l}\text { Pharmacy refill } \\
\text { adherence (SPDR) }\end{array}$} & \\
\cline { 3 - 4 } & & Yes & No & Total \\
\hline $\begin{array}{llll}\text { Self-reported } \\
\text { adherence }\end{array}$ & Yes & $294(80 \%)$ & $73(20 \%)$ & $367(100 \%)$ \\
(MARS-5) & & $89 \%$ & $80 \%$ & $87 \%$ \\
& No & $35(66 \%)$ & $18(34 \%)$ & $53(100 \%)$ \\
& & $11 \%$ & $20 \%$ & $13 \%$ \\
& Total & $329(78 \%)$ & $91(22 \%)$ & $420(100 \%)$ \\
& & $100 \%$ & $100 \%$ & $100 \%$ \\
\hline
\end{tabular}




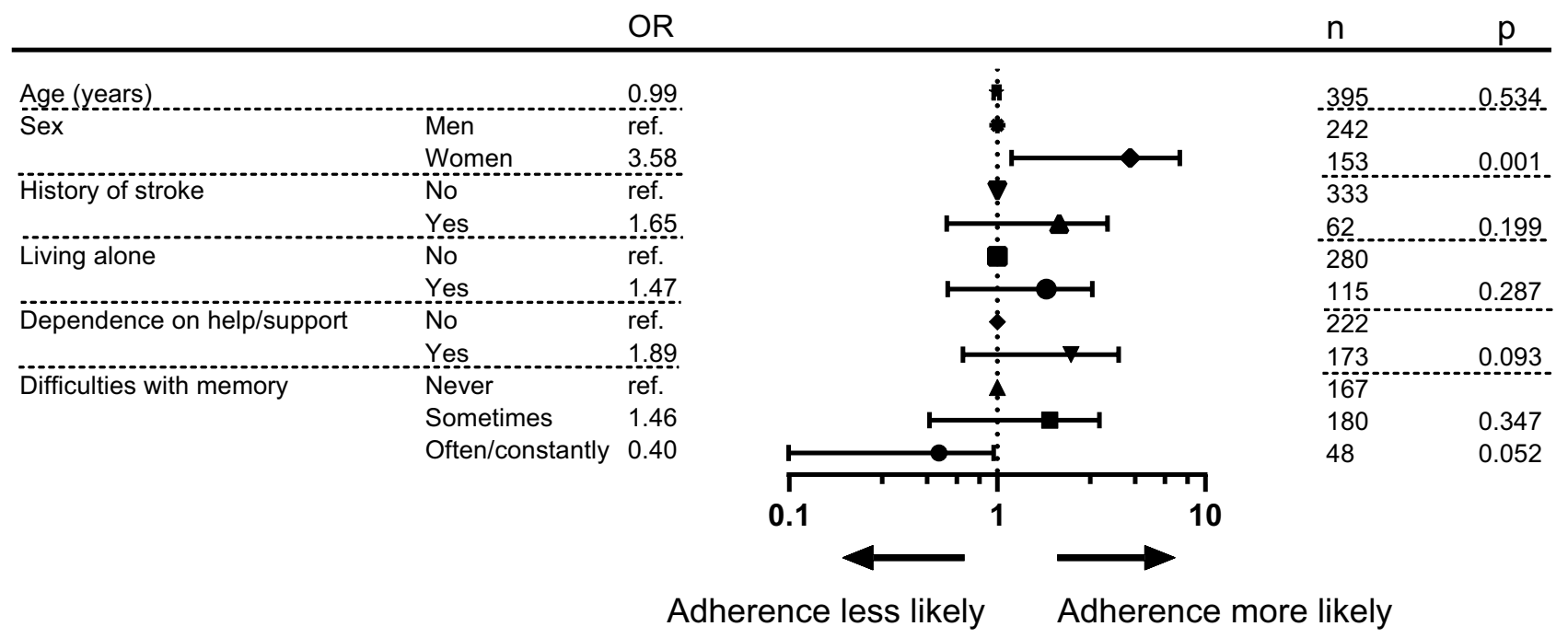

Fig. 2 Independent predictors of medication adherence associated with the Medication Adherence Report Scale (MARS-5). Participant characteristics are listed in the two left-hand columns. The odds ratios (OR) for each variable are listed next, and these ORs are then plotted

\section{Adherence to prescribed statins}

Our results show a slightly higher adherence compared with previous studies for persons with ischemic stroke. One reason could possibly be that the included participants were more adherent to statin therapy because the population only included those who fulfilled the questionnaire MARS-5, living at home at 3 months and were alive 2 years post stroke on a logarithmic scale. The two right-hand columns report the number of participants for each variable $(n)$ and whether the differences between the variables was significant $(p)$

and filled a prescription within 6 months of discharge. However, different follow-up times and methods used to assess adherence make it difficult to directly compare these studies [26]. In Yao et al. [27] and Wawruch et al. [28], approximately $60 \%$ of participants with atherosclerotic cardiovascular disease or ischemic stroke were adherent to statins according to prescription refills after 1 year and 3 years, respectively. Chung et al. [15] assessed self-reported statin

\begin{tabular}{|c|c|c|c|c|}
\hline & & OR & $\mathrm{n}$ & $\mathrm{p}$ \\
\hline Age (years) & & 0.97 & 392 & .0.013. \\
\hline \multirow[t]{2}{*}{ Sex } & Men & ref. & 242 & \\
\hline & Women & ح & 153 & 0.010 \\
\hline \multirow[t]{2}{*}{ History of stroke } & No & ref. & 333 & \\
\hline & Yes & 1.03 & 62 & 0.924 \\
\hline \multirow[t]{2}{*}{ Living alone } & No & ref. & 280 & \\
\hline & Yes. & 0.78 & 115 & 0.400 \\
\hline \multirow[t]{2}{*}{ Dependence on help/support } & No & ref. & 222 & \\
\hline & Yes. & 1.12 & 173 & 0.700 \\
\hline \multirow[t]{4}{*}{ Difficulties with memory } & Never & ref. & 167 & \\
\hline & Sometimes & 0.89 & 180 & 0.697 \\
\hline & Often/constantly & 0.77 & 48 & 0.545 \\
\hline & & dherence less likely & nore & \\
\hline
\end{tabular}

Fig. 3 Independent predictors of medication adherence based on data from the Swedish Prescribed Drug Register (SPDR). Participant characteristics are listed in the two left-hand columns. The odds ratios (OR) for each variable are listed next, and these ORs are then plotted on a logarithmic scale. The two right-hand columns report the number of participants for each variable $(n)$ and whether the differences between the variables was significant $(p)$ 
adherence with the 8-item Morisky Medication Adherence Scale in patients with acute ischemic stroke, showing that $66 \%$ were adherent after 6 months.

Studies with statins for primary and secondary prevention of coronary artery disease have shown that prescription refill adherence at the 2-year follow-ups was $25 \%$ and $40 \%$, respectively [29]. Naderi et al. [12] conducted a metaanalysis including more than 370,000 participants with or without coronary heart disease, showing that adherence to statin therapy was $57 \%$ and $76 \%$ for primary and secondary prevention after a median treatment period of 2 years, which is similar to our results.

Regarding the choice to study statins in the present study, and not, e.g., antihypertensives or anticoagulants also used in ischemic stroke prevention, were based on previous studies showing no significant differences in adherence or persistence to treatment between statins, anticoagulants, and antihypertensives [30, 31]. Further, because the SPDR does not contain data of daily doses, the estimates of adherence from SPDR were possible to perform more precisely in statins that merely are prescribed once per day.

\section{Various assessments of adherence}

Twenty percent of the respondents who were adherent according to self-reported adherence with MARS-5 were non-adherent according to pharmacy refills based on data from SPDR. Previous studies have shown that self-reported adherence assesses medication-taking behaviors, whereas pharmacy refill adherence assesses the medication-filling behaviors [32]. MARS-5 assesses whether individuals take their drugs after they are purchased (and can give insights into reasons for non-compliance), whereas SPDR counts the frequency of medication-filling behavior (that is, whether individuals fill their prescriptions in the first place, and then refill them over specified time intervals) [32, 33]. Even though these two assessments measure different aspects of medication adherence, it is clear that they can complement each other.

Our results are in line with previous studies that have shown that participants tend to overestimate their selfreported adherence to drug treatment or prescription filling compared to more objective assessments [33-39]. Furthermore, participants who are adherent according to self-reported assessments but non-adherent according to assessments that are more objective are, in some studies, defined as "falsepositive self-reported adherers". For instance, Tedla and Bautista [40] studied factors associated with false-positive self-reported adherence in 175 individuals who were starting antihypertensive drug therapy in primary care. In that study (and in accordance with our results), 20\% of the participants were classified as false-positive self-reported adherers. That study also found that falsely over-reported adherence was more likely in participants with anxiety and low educational levels, and less likely among smokers and those who suffered from blood pressure drug side effects.

The methods currently available for determining medication adherence differ widely [41, 42]. It is common in previous studies to assess medication availability, such as the proportion of days covered during a specified time period or over a period of refill intervals. In addition to the various methods, different terminology is also used. In this study, the term "pharmacy refill adherence" were chosen because it best fit the data obtained from SPDR. When estimating pharmacy refill adherence and choosing the length of the follow-up intervals, it is important to consider how poor implementation of the treatment or the length of gaps between treatments will affect the therapeutic benefit; for shorthand, these considerations are called the "forgiveness" of the drug [43]. In contrast to, e.g., antiretroviral drugs and anticoagulants, a short, temporary lapse in treatment of statins does not affect the therapeutic effect - in other words, statins are a "forgiving" treatment. Forgiving treatments have a cumulative effect: the better the implementation and persistence with treatment, the higher the benefit. In drugs with high forgiveness, it is possible to apply a longer grace period [41] and in that way minimize the risk of overestimating the non-adherence rate. To avoid overestimating non-adherence in the present study, a 3-month grace period was chosen in addition to the 3-month pharmacy refill intervals.

\section{Independent predictors of medication adherence}

In the multivariable logistic regression models, female sex was associated with medication adherence according to MARS-5, while male sex and younger age were associated with medication adherence based on data from SPDR. Several large studies and meta-analyses have shown that female patients are consistently more likely to be non-adherent to statin therapy and other cardiovascular long-term therapies when assessed with objective assessments [44-47]. However, in a validation study of MARS-5, female sex was associated with higher MARS-5, as well as a more objective assessment with medication possession rate [19].

The association between age and medication adherence has previously been studied. In a meta-analysis of 22 cohort studies, a U-shaped pattern of the relative risk of non-adherence was shown; the youngest $(<50$ years) and oldest ( $\geq 70$ years) had lower adherence as assessed with percentage of days covered, compared with the middle-aged (50-69 years) [46]. The study population in our study had an average age of $70 \pm 11$ years and considering that the number of drugs increase with age [45], polypharmacy could possibly be a predictor for non-adherence among included individuals. 
The study questionnaire contained some questions in which the respondents were asked to rate their current activity level or amount of help they need, e.g., dependence on relatives for help and support and difficulties with memory. These two variables did not show association with medication adherence in either of the multivariable analyses based on data from either MARS-5 or SPDR, although there was a trend towards lower adherence in participants who reported that they had often or always difficulties with memory in MARS-5. This result can probably be explained by the low need for help from relatives among the participants; the majority of these reported that they only needed partial support. In addition, only $12 \%$ rated that they often or always had difficulties with memory.

Other studies have revealed that a combination of patient and medical factors affect adherence to statin therapy. McGinnis et al. [48] showed that the most common reasons for statin discontinuation were follow-up and/or laboratory visits with a provider within 6 months after the statin prescription was initiated; adverse events, patient refusal, worry about developing adverse effects, the patient felt the treatment was unnecessary, physician-advised discontinuation and the patient preferred to manage their condition using diet and exercise. Similarly, Chee et al. [49] found that the major barriers to statin adherence were failure to appreciate the severity of potential complications, lack of perceived benefits, adverse events, medication cost, poor physician-patient relationship, and overestimation of the effectiveness of diet control as a treatment modality.

\section{Limitations}

The participants responded to the MARS-5 questionnaire 3 months after their stroke event, while SPDR followed up on refilled statin prescriptions during the 2 years post stroke. Because medication adherence often declined with time after diagnosis [12-14], the time aspect of the two assessments could have affected the results. The MARS-5 questionnaires presented to the participants considered their total medication list, not particular treatments or specific medications such as statins. In this study, an assumption was made that the participants were equally adherent to statins as to other long-term treatments that was measured by MARS-5. However, adherence may differ in some participants between different long-term drugs [50].

Only individuals who were alive 2 years after suffering mild ischemic stroke, who were conscious at stroke admission, and who were living at home 3 months after discharge were included. Therefore, the results cannot be extrapolated to the most frail patients, including those whose conditions deteriorated after the stroke or individuals with severe ischemic stroke. Likewise, other relevant cultural and socio-economic aspects differ between countries and the results may not be generalizable to populations outside Sweden.

\section{Conclusions}

This study found that the majority of the participants were classified as adherent, $87 \%$ according to MARS-5 and $78 \%$ based on data from SPDR. However, only $70 \%$ of the participants were adherent according to both MARS-5 and SPDR, and different predictors were associated with the different measurements. This result suggests that these assessments are measuring different aspects of adherence.

Supplementary information The online version contains supplementary material available at https://doi.org/10.1007/s00228-022-03284-4.

Author contribution Conceptualization: Helena Norberg, Maria Sjölander, Eva-Lotta Glader, Maria Gustafsson; Metodology: Helena Norberg, Maria Sjölander, Eva-Lotta Glader, Maria Gustafsson; Formal analysis and investigation: Helena Norberg; Writing — original draft preparation: Helena Norberg; Writing — review and editing: Maria Sjölander, Eva-Lotta Glader, Maria Gustafsson; Funding acquisition: Eva-Lotta Glader; Supervision: Maria Gustafsson.

Funding Open access funding provided by Umea University. This study was financially supported by grants from Apoteket AB and Västerbotten County Council.

Availability of data and materials The datasets used and/or analyzed during the current study are available from the corresponding author on reasonable request.

Code availability Not applicable.

\section{Declarations}

Ethics approval and consent to participate Ethics approval was obtained from the Ethical Review Board at Umeå University, Sweden (Reg.no 2011-375-31 M).

\section{Consent for publication Not applicable.}

Competing interests Helena Norberg has received lecture grants from Pfizer. Maria Sjölander, Eva-Lotta Glader, and Maria Gustafsson have no relevant financial or non-financial interests to disclose.

Open Access This article is licensed under a Creative Commons Attribution 4.0 International License, which permits use, sharing, adaptation, distribution and reproduction in any medium or format, as long as you give appropriate credit to the original author(s) and the source, provide a link to the Creative Commons licence, and indicate if changes were made. The images or other third party material in this article are included in the article's Creative Commons licence, unless indicated otherwise in a credit line to the material. If material is not included in the article's Creative Commons licence and your intended use is not permitted by statutory regulation or exceeds the permitted use, you will need to obtain permission directly from the copyright holder. To view a copy of this licence, visit http://creativecommons.org/licenses/by/4.0/. 


\section{References}

1. Simpson SH, Eurich DT, Majumdar SR, Padwal RS, Tsuyuki RT, Varney J et al (2006) A meta-analysis of the association between adherence to drug therapy and mortality. BMJ (Clinical research ed) $333: 15$. https://doi.org/10.1136/bmj.38875.675486.55

2. World Health Organization (2003) Adherence to Long-Term Therapies - Evidence for Action. WHO, Geneva

3. Kleindorfer DO, Towfighi A, Chaturvedi S, Cockroft KM, Gutierrez J, Lombardi-Hill D et al (2021) 2021 guideline for the prevention of stroke in patients with stroke and transient ischemic attack: a guideline from the American Heart Association/American Stroke Association. Stroke:Str0000000000000375. https://doi.org/10.1161/ str.0000000000000375.

4. Amarenco P, Bogousslavsky J, Callahan A 3rd, Goldstein LB, Hennerici M, Rudolph AE et al (2006) High-dose atorvastatin after stroke or transient ischemic attack. N Engl J Med 355:549_ 559. https://doi.org/10.1056/NEJMoa061894

5. Amarenco P, Kim JS, Labreuche J, Charles H, Abtan J, Béjot Y et al (2020) A comparison of two LDL cholesterol targets after ischemic stroke. N Engl J Med 382:9. https://doi.org/10.1056/ NEJMoa1910355

6. Visseren FLJ, Mach F, Smulders YM, Carballo D, Koskinas KC, Bäck M et al (2021) 2021 ESC Guidelines on cardiovascular disease prevention in clinical practice. Eur Heart J 42:3227-3337. https://doi.org/10.1093/eurheartj/ehab484

7. Kim J, Lee HS, Nam CM, Heo JH (2017) Effects of statin intensity and adherence on the long-term prognosis after acute ischemic stroke. Stroke 48:2723-2730. https://doi.org/10.1161/strokeaha. 117.018140

8. Baigent C, Keech A, Kearney PM, Blackwell L, Buck G, Pollicino $\mathrm{C}$ et al (2005) Efficacy and safety of cholesterol-lowering treatment: prospective meta-analysis of data from 90,056 participants in 14 randomised trials of statins. Lancet (London, England) 366:12671278. https://doi.org/10.1016/s0140-6736(05)67394-1

9. Yeo SH, Toh M, Lee SH, Seet RCS, Wong LY, Yau WP (2020) Impact of medication nonadherence on stroke recurrence and mortality in patients after first-ever ischemic stroke: Insights from registry data in Singapore. Pharmacoepidemiol Drug Saf 29:538-549. https://doi.org/10.1002/pds.4981

10. Kumbhani DJ, Steg PG, Cannon CP, Eagle KA, Smith SC Jr, Hoffman E et al (2013) Adherence to secondary prevention medications and four-year outcomes in outpatients with atherosclerosis. Am J Med 126:693-700.e1. https://doi.org/10.1016/j.amjmed. 2013.01.033

11. Vitturi BK, Gagliardi RJ (2021) The influence of statin withdrawal and adherence on stroke outcomes. Neurol Sci 42:2317-2323. https://doi.org/10.1007/s10072-020-04790-y

12. Naderi SH, Bestwick JP, Wald DS (2012) Adherence to drugs that prevent cardiovascular disease: meta-analysis on 376,162 patients. Am J Med 125:882-7.e1. https://doi.org/10.1016/j.amjmed.2011. 12.013

13. Barber N, Parsons J, Clifford S, Darracott R, Horne R (2004) Patients' problems with new medication for chronic conditions. Qual Saf Health Care 13:172-175. https://doi.org/10.1136/qhc. 13.3.172

14. Benner JS, Glynn RJ, Mogun H, Neumann PJ, Weinstein MC, Avorn J (2002) Long-term persistence in use of statin therapy in elderly patients. JAMA 288:455-461. https://doi.org/10.1001/ jama.288.4.455

15. Chung PW, Yoon BW, Lee YB, Shin BS, Kim HY, Park JH et al (2018) Medication adherence of statin users after acute ischemic stroke. Eur Neurol 80:106-114. https://doi.org/10.1159/000493530

16. Xu T, Yu X, Ou S, Liu X, Yuan J, Chen Y (2017) Statin adherence and the risk of stroke: a dose-response meta-analysis. CNS Drugs 31:263-271. https://doi.org/10.1007/s40263-017-0420-5
17. Wroe AL (2002) Intentional and unintentional nonadherence: a study of decision making. J Behav Med 25:355-372. https://doi. org/10.1023/a:1015866415552

18. Tommelein E, Mehuys E, Van Tongelen I, Brusselle G, Boussery K (2014) Accuracy of the Medication Adherence Report Scale (MARS-5) as a quantitative measure of adherence to inhalation medication in patients with COPD. Ann Pharmacother 48:589595. https://doi.org/10.1177/1060028014522982

19. Lin CY, Ou HT, Nikoobakht M, Broström A, Årestedt K, Pakpour AH (2018) Validation of the 5-Item Medication Adherence Report Scale in older stroke patients in Iran. J Cardiovasc Nurs 33:536543. https://doi.org/10.1097/jcn.0000000000000488

20. van de Steeg N, Sielk M, Pentzek M, Bakx C, Altiner A (2009) Drug-adherence questionnaires not valid for patients taking bloodpressure-lowering drugs in a primary health care setting. J Eval Clin Pract 15:468-472. https://doi.org/10.1111/j.1365-2753.2008. 01038.x

21. Mahler C, Hermann K, Horne R, Ludt S, Haefeli WE, Szecsenyi $\mathrm{J}$ et al (2010) Assessing reported adherence to pharmacological treatment recommendations. Translation and evaluation of the Medication Adherence Report Scale (MARS) in Germany. J Eval Clin Pract 16:574-579. https://doi.org/10.1111/j.1365-2753.2009. 01169.x

22. Ladova K, Matoulkova P, Zadak Z, Macek K, Vyroubal P, Vlcek J et al (2014) Self-reported adherence by MARS-CZ reflects LDL cholesterol goal achievement among statin users: validation study in the Czech Republic. J Eval Clin Pract 20:671-677. https://doi. org/10.1111/jep.12201

23. Sjölander M, Eriksson M, Glader EL (2013) The association between patients' beliefs about medicines and adherence to drug treatment after stroke: a cross-sectional questionnaire survey. BMJ Open 3:e003551. https://doi.org/10.1136/bmjopen-2013-003551

24. Chan AHY, Horne R, Hankins M, Chisari C (2020) The Medication Adherence Report Scale: A measurement tool for eliciting patients' reports of nonadherence. Br J Clin Pharmacol 86:12811288. https://doi.org/10.1111/bcp.14193

25. Wettermark B, Hammar N, Fored CM, Leimanis A, Otterblad Olausson P, Bergman U et al (2007) The new Swedish Prescribed Drug Register-opportunities for pharmacoepidemiological research and experience from the first six months. Pharmacoepidemiol Drug Saf 16:726-735. https://doi.org/10.1002/pds.1294

26. Sattler EL, Lee JS, Perri M 3rd (2013) Medication (re)fill adherence measures derived from pharmacy claims data in older Americans: a review of the literature. Drugs Aging 30:383-399. https:// doi.org/10.1007/s40266-013-0074-z

27. Yao X, Shah ND, Gersh BJ, Lopez-Jimenez F, Noseworthy PA (2020) Assessment of trends in statin therapy for secondary prevention of atherosclerotic cardiovascular disease in US adults from 2007 to 2016. JAMA Netw Open 3:e2025505. https://doi. org/10.1001/jamanetworkopen.2020.25505

28. Wawruch M, Zatko D, Wimmer G Jr, Luha J, Hricak V Jr, Murin J et al (2017) Patient-related characteristics associated with nonpersistence with statin therapy in elderly patients following an ischemic stroke. Pharmacoepidemiol Drug Saf 26:201-207. https://doi.org/10.1002/pds.4148

29. Jackevicius CA, Mamdani M, Tu JV (2002) Adherence with statin therapy in elderly patients with and without acute coronary syndromes. JAMA 288:462-467. https://doi.org/10.1001/jama.288.4.462

30. Sjölander M, Eriksson M, Glader EL (2012) Few sex differences in the use of drugs for secondary prevention after stroke: a nationwide observational study. Pharmacoepidemiol Drug Saf 21:911-919. https://doi.org/10.1002/pds.2268

31. Lank RJ, Lisabeth LD, Levine DA, Zahuranec DB, Kerber KA, Shafie-Khorassani F et al (2019) Ethnic differences in 90-day poststroke medication adherence. Stroke 50:1519-1524. https:// doi.org/10.1161/strokeaha.118.024249 
32. Krousel-Wood M, Holt E, Joyce C, Ruiz R, Dornelles A, Webber LS et al (2015) Differences in cardiovascular disease risk when antihypertensive medication adherence is assessed by pharmacy fill versus self-report: the Cohort Study of Medication Adherence among Older Adults (CoSMO). J Hypertens 33:412-420. https:// doi.org/10.1097/hjh.0000000000000382

33. Steiner JF (2012) Self-reported adherence measures: what do they assess and how should we use them? Med Care 50:1011-1012. https://doi.org/10.1097/MLR.0b013e318270abaf

34. Ding R, Zeger SL, Steinwachs DM, Ortmann MJ, McCarthy ML (2013) The validity of self-reported primary adherence among Medicaid patients discharged from the emergency department with a prescription medication. Ann Emerg Med 62:225-234. https://doi.org/10.1016/j.annemergmed.2013.01.026

35. Simoni JM, Huh D, Wang Y, Wilson IB, Reynolds NR, Remien RH et al (2014) The validity of self-reported medication adherence as an outcome in clinical trials of adherence-promotion interventions: Findings from the MACH14 study. AIDS Behav 18:2285-2290. https://doi.org/10.1007/s10461-014-0905-x

36. Sayner R, Carpenter DM, Blalock SJ, Robin AL, Muir KW, Hartnett ME et al (2015) Accuracy of patient-reported adherence to glaucoma medications on a visual analog scale compared with electronic monitors. Clin Ther 37:1975-1985. https://doi.org/10.1016/j.clinthera.2015.06.008

37. Daniels T, Goodacre L, Sutton C, Pollard K, Conway S, Peckham D (2011) Accurate assessment of adherence: self-report and clinician report vs electronic monitoring of nebulizers. Chest 140:425432. https://doi.org/10.1378/chest.09-3074

38. Schaefer MR, Wagoner ST, Young ME, Rawlinson AR, Kavookjian J, Shapiro SK et al (2019) Subjective versus objective measures of medication adherence in adolescents/young adults with attention-deficit hyperactivity disorder. J Dev Behav Pediatr 40:54-59. https://doi.org/10.1097/dbp.0000000000000602

39. Bright EE, Stanton AL (2019) Correspondence between objective and self-reported endocrine therapy adherence among women with breast cancer. Ann Behav Med 53:849-857. https://doi.org/ 10.1093/abm/kay094

40. Tedla YG, Bautista LE (2017) Factors associated with false-positive self-reported adherence to antihypertensive drugs. J Hum Hypertens 31:320-326. https://doi.org/10.1038/jhh.2016.80

41. Andrade SE, Kahler KH, Frech F, Chan KA (2006) Methods for evaluation of medication adherence and persistence using automated databases. Pharmacoepidemiol Drug Saf 15:565-74; discussion 75-7. https://doi.org/10.1002/pds.1230.

42. Sikka R, Xia F, Aubert RE (2005) Estimating medication persistency using administrative claims data. Am J Manag Care 11:449-457

43. Rasmussen L, Pratt N, Hansen MR, Hallas J, Pottegård A (2018) Using the "proportion of patients covered" and the Kaplan-Meier survival analysis to describe treatment persistence. Pharmacoepidemiol Drug Saf 27:867-871. https://doi.org/10.1002/pds.4582

44. Olmastroni E, Boccalari MT, Tragni E, Rea F, Merlino L, Corrao $G$ et al (2020) Sex-differences in factors and outcomes associated with adherence to statin therapy in primary care: Need for customisation strategies. Pharmacol Res 155:104514. https://doi. org/10.1016/j.phrs.2019.104514

45. Manteuffel M, Williams S, Chen W, Verbrugge RR, Pittman DG, Steinkellner A (2014) Influence of patient sex and gender on medication use, adherence, and prescribing alignment with guidelines. J Womens Health (Larchmt) 23:112-119. https://doi.org/10.1089/ jwh.2012.3972

46. Mann DM, Woodward M, Muntner P, Falzon L, Kronish I (2010) Predictors of nonadherence to statins: a systematic review and meta-analysis. Ann Pharmacother 44:1410-1421. https://doi.org/ 10.1345/aph.1P150

47. Lewey J, Shrank WH, Bowry AD, Kilabuk E, Brennan TA, Choudhry NK (2013) Gender and racial disparities in adherence to statin therapy: a meta-analysis. Am Heart J 165(665-78):78. e1. https://doi.org/10.1016/j.ahj.2013.02.011

48. McGinnis B, Olson KL, Magid D, Bayliss E, Korner EJ, Brand DW et al (2007) Factors related to adherence to statin therapy. Ann Pharmacother 41:1805-1811. https://doi.org/10.1345/aph.1K209

49. Chee YJ, Chan HH, Tan NC (2014) Understanding patients' perspective of statin therapy: can we design a better approach to the management of dyslipidaemia? A literature review. Singapore Med J 55:416-421. https://doi.org/10.11622/smedj.2014099

50. Steiner JF (2012) Rethinking adherence. Ann Intern Med 157:580-585. https://doi.org/10.7326/0003-4819-157-8-20121 $0160-00013$

Publisher's Note Springer Nature remains neutral with regard to jurisdictional claims in published maps and institutional affiliations. 